\title{
Stem-cell pioneer banks on future therapies
}

\section{Japanese researcher plans cache of induced stem cells to supply clinical trials.}

\section{BY DAVID CYRANOSKI}

$\mathrm{P}$ rogress toward stem-cell therapies has been frustratingly slow, delayed by research challenges, ethical and legal barriers and corporate jitters. Now, stem-cell pioneer Shinya Yamanaka of Kyoto University in Japan plans to jump-start the field

$\sum$ by building up a bank of stem cells for therapeutic use. The bank would store dozens of lines of induced pluripotent stem (iPS) cells, putting Japan in an unfamiliar position: at the forefront of efforts to introduce a pioneering biomedical technology.

A long-held dream of Yamanaka's, the iPS Cell Stock project received a boost last month, when a Japanese healthministry committee decided to allow the creation of cell lines from the thousands of samples of fetal umbilical-cord blood held around the country. Yamanaka's plan to store the cells for use in medicine is "a bold move", says George Daley, a stem-cell biologist at Harvard Medical School in Boston, Massachusetts. But some researchers question whether iPS cells are ready for the clinic.

Yamanaka was the first researcher to show, in 2006, that mature mouse skin cells could be prodded into reverting to stem cells ${ }^{1}$ capable of forming all bodily tissues. The experiment, which he repeated $^{2}$ with human cells in 2007 , could bypass ethical issues associated with stem cells derived from embryos, and the cells could be tailor-made to match each patient, thereby avoiding rejection by the immune system.

Japan is pumping tens of millions of dollars every year into eight long-term projects to translate iPS cell therapies to the clinic, including a US\$2.5-million-per-year effort to relieve Parkinson's disease at Kyoto University's Center for iPS Cell Research and Application (CiRA), which Yamanaka directs. That programme is at least three years away from clinical trials. The first human clinical trials using iPS cells, an effort to repair diseased retinas, are planned for next year at the RIKEN Center for Developmental Biology in Kobe.

Those trials will not use cells from Yamanaka's Stock. But if they or any other iPS cell trials succeed, demand for the cells will explode, creating a supply challenge. Deriving and testing iPS cells tailored to individual patients could take six months for each cell line and cost tens of thousands of dollars.

Yamanaka's plan is to create, by 2020, a standard array of 75 iPS cell lines that are a

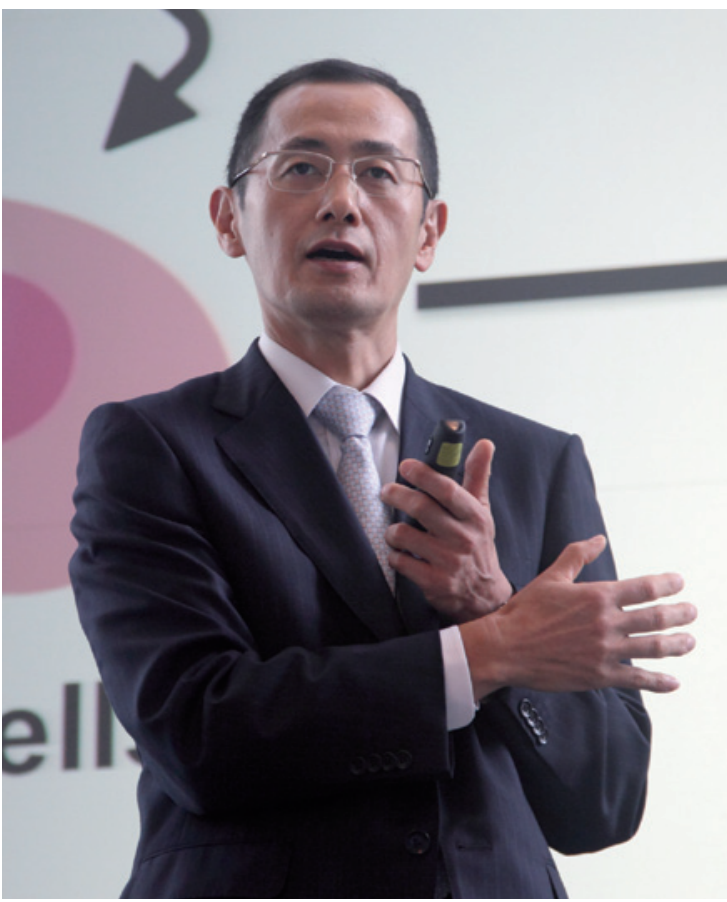

Shinya Yamanaka aims to produce cell lines from fetal blood cells.

leukaemia. Each bank will determine for itself whether further consent is needed.

Yamanaka has already built a cell-processing facility on the second floor of CiRA and is now applying for ethics approval from Kyoto University to create the stock. Takafumi Kimura, a CiRA biologist and head of the project's HLA analysis unit, says that the team hopes to derive the first line, carrying a set of HLA proteins that matches that of $8 \%$ of Japan's population, by next March

Yamanaka's project has an advantage in that genetic diversity in Japan is relatively low; elsewhere, therapeutic banks would have to be larger and costlier. Most iPS banks outside Japan specialize in cells from people with diseases, for use in research rather than treatment. The California Institute for Regenerative Medicine (CIRM) in San Francisco, for example, plans to bank some 3,000 cell lines for distribution to researchers.

Alan Trounson, president of CIRM, says that unresolved research questions about iPS cells make it "premature" to begin therapeutic trials. "We don't have complete pictures of how good they would be," he says, noting that such cells accumulate mutations and other defects as they are produced from differentiated cells. Irving Weissman, a stemcell biologist at Stanford University in California, warns that iPS cells derived from blood cells have been shown to

good enough match to be tolerated by $80 \%$ of the population. To do that, Yamanaka needs to find donors who have two identical copies of each of three key genes that code for immunerelated cell-surface proteins called human leukocyte antigens (HLAs). He calculates that he will have to sift through samples from some 64,000 people to find 75 suitable donors.

Using blood from Japan's eight cord-blood banks will make that easier. The banks hold some 29,000 samples, all HLA-characterized, and Yamanaka is negotiating to gain access to those that prove unusable for other medical procedures. One issue remains unresolved: whether the banks need to seek further informed consent from donors, most of whom gave the blood under the understanding that it would be used for treating or studying

\section{form tumours ${ }^{3}$.}

Kimura says that the answer is to carefully avoid the white blood cells that cause tumours when deriving the cell lines, and he stresses that all safety concerns will be addressed. "We're building a national resource. It has to be safe and have the confidence of the people."

Daley, who last month toured CiRA's facility, calls it "nothing short of spectacular, pristine, perfect". He agrees that proving the safety of the cells will be tough, but he is enthusiastic about the effort. "It's clear they're readying themselves for a big project," he says.

1. Takahashi, K. \& Yamanaka, S. Cell 126, 663-676 (2006).

2. Takahasi, K. et al. Cell 131, 861-872 (2007).

3. Serwold, T. et al. Proc. Natl Acad. Sci. USA 107, 8939-18943 (2010). 